\title{
: La soberanía política en el krausismo español
}

\section{Political sovereignty in spanish krausism}

\author{
MÓNICA SORIA MOYA. \\ Profesora colaboradora doctora. \\ Universidad CEU-Cardenal Herrera. \\ monica.soria1@uchceu.es \\ DOI: https://doi.org/10.7203/cc.2.22177 \\ Fecha de recepción: 11/10/2021 \\ Fecha de aceptación: 05/11/2021
}

\section{Resumen}

El estudio de la soberanía política ha sido objeto de investigación entre los clásicos del pensamiento del derecho público europeo, fuertemente vinculado con la noción de la personalidad jurídica del Estado entorno a la doctrina francesa de "nación-persona" y la doctrina alemana de "naciónórgano", configurando en el constitucionalismo español la fórmula jurídicopolítica de la personalidad y la titularidad del poder del Estado en torno a los partidarios bien de la Soberanía Nacional bien de la Soberanía compartida en la Corona y las Cortes. Bajo la influencia krausista resulta de interés aproximarnos al concepto de soberanía como función del Estado que nos ofrece Adolfo Posada; destacado iuspublicista europeo que, ante la crisis del liberalismo doctrinario y la incipiente cuestión social, supo compaginar la teoría y la acción desde una posición éticopolítica hacia un Estado constitucional para garantizar el orden social.

\section{Palabras clave}

Constitución; Democracia; Soberanía Nacional; Soberanía; Krausismo; Organicismo social; Sociedad; Liberalismo.

\begin{abstract}
The study of political sovereignty has been the subject of research among the classics of European public law thought, strongly linked to the notion of the legal personality of the state around the French doctrine of "nation-person" and the German doctrine of "nation organ", configuring in Spanish constitutionalism the juridicalpolitical legal formula of the personality and ownership of the power of the State around the supporters of either National Sovereignty or shared Sovereignty in the Crown and the Courts. Under the Krausist influence it is of interest to approach the concept of sovereignty as a function of the state offered by Adolfo Posada; outstanding European publicist who, in the face of the crisis of doctrinaire liberalism and the incipient social question, knew how to combine theory and action from an ethicalpolitical position towards a constitucional State to guarantee the social order.
\end{abstract}

\section{Keywords}

Constitution; Democracy; National Sovereignty; Sovereignty; Krausism; Social Organicism; Society; Liberalism. 


\section{La influencia krausista en la teoría de Estado. - II. El libe- ralismo democrático en la teoría orgánica del Estado. - III. La soberanía política como función del Estado. - IV. Epílogo. Bibliografía.}

La soberanía política tiene su raíz en la soberanía social del todo que la engendra

Posada, "La soberanía", BILE, 1915

\section{La influencia krausista en la teoría de Estado}

Como señalara el conde de Mirabeau en 1789 "le mot peuple signifie necessairement ou trop ou trop peu. C'est un mot qui se prête à tout" ${ }^{\prime \prime}$, pasando de ser una palabra indefinible, a ser revalorizada a partir de 1808, convirtiéndola en el centro del discurso político del liberalismo bajo el principio de soberanía nacional, sin perjuicio de su rápida efervescencia ante su vulnerabilidad por la manipulación de los grupos minoritarios.

La historia del pensamiento político nos enseña cómo la aspiración de libertad, justicia, igualdad, democracia o autonomía han sido anhelados desde antiguo, al ser axiomas que presentan ambigüedad susceptible de debate y que ha enfrentado a la monarquía, institución tradicional e histórica, encarnación del antiguo régimen, defensora del poder político dependiente de una instancia única y omnipotente, frente al liberalismo partidario de la soberanía nacional que deja constancia expresa o tácita de la cesión del poder al Estado, con la existencia de límites necesarios con los que controlar su ejercicio mediante una ley superior.

Las distintas teorías del Estado que han influido en la estructura institucional de los países constitucionales desde el siglo XIX, frente al sistema histórico del absolutismo monárquico, incorporan los principios de liberalismo democrático tales como la soberanía nacional y la separación de poderes acotando las propuestas liberales a "los que consideran que la titularidad de la soberanía reside en la nación y los que la han atribuido a la Corona y a las Cortes", a fin de hacer compatible el rey soberano con el súbdito libre, en virtud de la cual la soberanía reside a la vez en la nación y en el monarca (Morán Martín, 2016: 361375).

Esta idea de semilegitimidad evidenció una abducción tanto frente al absolutismo como frente a la democracia al ver incompatibles el derecho del pueblo a gobernarse a sí mismo con los caracteres de la monarquía tradicional dado que, "para que la monarquía se haga compatible con la soberanía nacional es preciso revertir al Estado la Corona" (Azcárate, 1978: 106), proclamando en el

1 Citado por Fuentes, 2004: 95. 
artículo tercero de la Constitución de 1812 un poder nacional constituyente por el cual "la soberanía nacional reside esencialmente en la Nación y por lo mismo pertenece a ésta exclusivamente el derecho de establecer sus leyes fundamentales". Si bien, el respeto del principio liberal no logró alcanzar en España, frente a la adaptación pacífica de otros pueblos, el respeto deseable por la mixtificación de la voluntad del pueblo ante un sistema representativo adulterado que, junto a la perdida colonial de 1898 terminó gestando una conciencia de crisis y de fracaso por casi todo lo existente ante el llamado "problema de España", poniendo de manifiesto la interesada sobrevaloración política hacia un pueblo indiferente.

Esta quietud social tiende a desvanecerse ante la propuesta antiindividualista y europeizante que Julián Sanz del Río hiciera de las nuevas corrientes del pensamiento científico centroeuropeo. En especial, la traducción en 1860 del Ideal de la humanidad para la vida, de Karl Christian Friedrich Krause, generó un movimiento de renovación éticopedagógica bajo una concepción racionalista frente al pensamiento tradicional que, a través del "evangelio del jurista" obra de Giner de los Ríos titulada Principios de derecho natural (1871), aportó en sus discípulos un nuevo derecho político, una "revelación" por la inspiración moral de sus ideas, al apostar por un Derecho del Estado (cuando se le denomina político) "de abolengo krausista, sin duda por su base ética, sus supuestos metafísicos y su sentido esencialmente orgánico, pero de una profunda originalidad frente a las tendencias entonces invasoras del organicismo sociológico" (Posada, 1980).

El curso que sobre Principios de derecho político impartiera Giner de los Ríos hacia 18801881 en la Institución Libre de Enseñanza, aportó en Posada una "verdadera Filosofía del Derecho del Estado" en las concepciones filosóficas de Schelling y Krause (Posada, 1986: 147) y le permitió publicar en 1884, "quizá fuera un poco precipitada" (Posada, 1983: 227)2, su primera obra, Principios de derecho político. Introducción, en la que, bajo una concepción sistemática, propone estudiar el Estado totalmente considerado, de manera interdisciplinar desde la filosofía del derecho político por la que reflexionar sobre el ideal del Estado y de su vida jurídica, como con un estudio histórico porque, en opinión de Posada, la historia y la filosofía del derecho político se completan y auxilian: "la una sin la otra, desde el punto de vista del hombre, son inconcebibles, porque el hombre... no puede filosofar sin tener como base el conocimiento de los hechos, y tampoco puede conocer los hechos bien sin saber algo de la idea que les sirve de fondo" (Posada, 1884: 53). Así como, desde el punto de vista de la filosofía de la historia del derecho político. La importancia de la obra le valió ser declarada de utilidad para la enseñanza por Real Orden de 20 de abril de $1889^{3}$.

En 1893, animado por Victoriano Suárez ${ }^{4}$, Posada profundiza en las investigaciones publicadas en los Principios, y publica sus estudios y notas de diez años

2 Sin perjuicio de que en 1881 se publicara la versión española de La Lucha por el Derecho de von Ihering con un prólogo de Clarín.

3 Con fecha de 17 de enero de 1885, Posada propone que el libro le sirva como mérito en su carrera profesional, solicitando del Consejo de Instrucción Pública informe sobre el valor científico de la obra. Con fecha de 13 de abril de 1889 la sección segunda del Consejo de Instrucción Pública considera el libro “...de valor, como obra de consulta, por lo bien meditado, lo copioso de la doctrina y el gran conocimiento que entraña de todo lo más serio que se ha escrito sobre ciencia política, principalmente en los modernos tiempos. En tal concepto, la sección segunda no ve inconveniente en que la obra del sr. Posada se declare de utilidad para la enseñanza y sirva al autor de mérito en su carrera". Dictamen del consejo ratificado por el ministro de Fomento, A. G. A. 7/7491.

4 Como Señal Posada en sus memorias, refiriéndose a don Victoria Suárez como "mi paisano", fue su editor y librero (Posada, 1983: 275). 
de docencia en el Tratado de Derecho Político, su obra más relevante compuesta por tres volúmenes ${ }^{5}$, con sucesivas ediciones completamente revisadas, a la que consideró "obra capital de mi larga vida de profesor, de investigador y de publicista..." (Posada, 1983: 277), y en las que fue gestando la interpretación jurídica y política del Estado que le permitirá abogar por la soberanía política desde una concepción organicista en la soberanía social.

Con la publicación del Tratado, Posada aportó al pensamiento político del momento la división bipartita, mantenida por Bluntschli. Y así, frente a la anterior división tripartita defendida por Ahrens y acogida por Santamaría de Paredes ${ }^{6}$, Posada distinguió entre la Teoría del Estado -al que dedica su primer tomo-en la que estudia el Estado como un organismo de un sistema de funciones con el que garantizar el ordenamiento jurídico a partir de una conciencia éticosocial. Su segunda parte, dedicada al derecho político moderno, se ocupa del Derecho Constitucional comparado de los principales países de Europa y América, en el que presenta el Derecho Constitucional, "no como un mero resultado estructural, en la pura organización de las magistraturas circunstanciales, sino como entidad sociológica, desde el punto de vista de la actividad y de las funciones sociales que el Estado entraña" (Posada, 1897: 10-11). El tercero de sus volúmenes -que tras la primera tirada no se reimprimió y del que Posada quedó insatisfechoconstituye una "Guía para el estudio y aplicación del Derecho Constitucional de Europa y América (cuestionarios, textos y bibliografía)", en el que analiza el derecho constitucional según las constituciones vigentes en los estados modernos. Con él, y sin llegar a funcionar como libro de texto, sí que alcanzó un éxito científico en la incipiente cultura constitucional, al tatar de renovar los contenidos de la disciplina para convertirla en disciplina jurídica de carácter sociológico, frente a la visión histórica y dogmática del Estado explicada por Colmeiro en su Curso de derecho político, con el que se aportó a los estudiantes de aquellos años el saber político exigido (Posada, 1888: 75-76) ${ }^{7}$, y donde me enteré, como afirma Posada (1983), de que "la soberanía de los pueblos es la soberanía del puñal".

Desde su cátedra de Elementos de derecho político y administrativo español, Posada explicó el Estado desde una dimensión orgánica, como una realidad social ordenada políticamente para tutelar el Derecho. Una explicación más profunda del Estado que, sin ser Metafísica, trascendiera del mundo físico -más allá de la Física- en las exigencias de la naturaleza ética del ser humano, y permitiera al estudiante comprender la realidad en la que los acontecimientos políticos se producen (Soria, 2004: 503-515). Para ello, durante cuarenta y ocho años de cátedra, desde la universidad de Oviedo y en Madrid, profundizará en la relación SociedadDerechoEstado y la intervención directa de éste en el devenir social organizado formalmente a través de un texto constitucional como declaración jurídica del mismo.

5 El primero de los tomos se titula "Teoría del Estado", el segundo "Derecho Constitucional comparado de los principales estados de Europa y América" y el tercero "Guía para el estudio y aplicación del derecho constitucional de Europa y América (cuestionarios, textos y bibliografía)".

6 Santamaría de Paredes definía el derecho constitucional como "el derecho que determina la naturaleza y organización fundamental del Estado", bajo una triple vertiente histórica, filosófica y filosóficahistórica, esta última, encargada de estudiar a la vez la organización ideal, así como la organización positiva (Varela, 2015: 78).

7 El derecho público que se enseñaba en las facultades de derecho, de 1845 a 1868, estaba dominado por la figura de Colmeiro, y por su libro Elementos de derecho político y administrativo que, era llamado "Colmeiro pequeño", frente a los dos tomos de su Derecho administrativo. Véase Gallego Anabitarte (2002: 306) y Posada (1983: 75). 
La realidad sociopolítico de la España de entre siglos se encontró condicionada con la incipiente aparición de la denominada cuestión social. El desastre del 98, tras la pérdida colonial, bajo un contexto social de miseria social agudizado por el ascenso del nacionalismo y el debilitamiento del turno de los partidos dinásticos, derivó en una crisis de conciencia nacional y con ella el necesario regeneracionismo social al que se trató de dar una respuesta democratizadora por parte de los intelectuales krausistas.

Frente a los intentos de regeneración "desde dentro", sin voluntad por transformar la estructura del precario sistema de la Restauración, se ofrece desde la cátedra de influencia krausista, una reforma ética por la que tender hacia la socialización del Estado, vinculando el estudio del derecho político con la sociología, la filosofía, la historia y otras ramas del saber científico que permitieran transformar un enfoque formalista del Estado, sintetizado en un texto constitucional con alusión a "las funciones y órganos del Estado, para cumplir su misión jurídica y social" (Posada, 1897: XII), sin reflexionar en la esencia con la que inquirir el concepto, el origen, los elementos y su fin. De este modo, el Estado había quedado referido a un organicismo autoritario representado por el alcalde, el ejército, el recaudador de impuestos...; en definitiva, en quien limitaba la libertad del elemento neutro al detentar el poder de gobernar desde una concepción materialista, y convertirlo en instrumento de dominación, confundiendo el término Gobierno, con otro muy distinto como lo es el Estado, y que de la conjunción de ambos se permite hablar del "gobierno del Estado".

La forma lo ha sido casi todo; desgraciadamente lo es todavía... Querer abstraer la política formal de la política sustancial, equivale a pretender construir una máquina sin tener en cuenta el fin a que ha de servir... (Giner de los Ríos, 1875: 201-225, 207-208).

El fundamento sociodemocrático de influencia krausista matiza la dualidad de seres distintos en la relación jurídica a que tiende el orden social, el uno superior -al referirse al Estado-, y el otro inferior -alusivo al individuo- porque el "hombrepersona" se integra en un "organismo social vivo" que constituye una unidad soberana. Ahora bien, se permite discernir entre gobierno al referirse al "estado oficial", como conjunto de personas que llevan a cabo la acción política del Estado, del "estado no oficial", como entidad abstracta y ética que representa al Estado en sentido amplio; es decir, el conjunto de personas que lo integran -la sociedad-, y que se relacionan con el gobierno a través de sus representantes, como poder constituido. Esta distinción permite señalar la dualidad SociedadEstado, donde el término genérico "sociedad" recibe el nombre de Estado en el modelo constitucional, cuando adopta una organización determinada para garantizar el cumplimiento del derecho. De este modo, la función gubernativa queda reducida a una función del Estado -función ejecutiva-, mientras que el término Estado, en sentido estricto, lo refieren a la sociedad en la que el gobierno ejerce su función (Posada, n.d. a: 40).

El tradicional doctrinarismo abstracto condujo al error de reducir el estudio del Estado a su aspecto formal y considerarlo como algo por todos conocido y del que todos podían opinar. Sin embargo, su estudio exigía un análisis más detenido para descubrir su esencia, superando toda definición formalista que tendía a definirlo en los términos siguientes: “ ¿El estado?, pero hombre, el estado es lo que todos sabemos, gozamos y sufrimos" (Posada, 1934: 26). Si bien esta afirmación puede ser bastante para ciertos fines, es insuficiente para los fines 
superiores del conocimiento científico, debiendo plantearse como problema esencial, la idea del Estado, "porque desde que el hombre se ha propuesto penetrar con su inteligencia la esencia, el ser de las cosas humanas... el estado ha sido, y todo hace pensar que continuará siendo, objeto de la reflexión y excitante de la curiosidad espiritual" (Ibid.: 10). Frente a él y sobre la constitución monárquica de 1876 se trató de conocer lo que el Estado es y el porqué de su existencia dado que, "la idea fundamental de la política, es ante todo e inmediatamente no la de orden, ni la de libertad, ni la de equilibrio de la libertad en el orden, sino la de su objeto mismo, la idea del estado..." (Giner de los Ríos, 1875: 76 y ss.). Sin tener una idea clara de lo que el Estado es y representa, difícilmente se podía profundizar en un estudio formal, al carecer de una base sólida en la que apoyar su concepto; lo que facilitaría las continuas variaciones en el modo de entenderlo en un proceso de democratización político y social.

De este modo, frente al viejo liberalismo doctrinario, y por influjo del movimiento renovador de la filosofía alemana, se empieza a explicar un liberalismo democrático formulando una "idea pura del Estado", de raíz ética y contenido social que da prioridad al "hombre interior" miembro del orden social, y trata de definirlo desde una concepción jurídica, al considerar el Estado como unidad autónoma de orden jurídico cuya observancia depende del ser racional. Esta definición de Estado, como orden social garante del ordenamiento jurídico fue defendida por Posada, porque al igual que señalara Azcárate:

De un modo directo o de un modo indirecto, a todos es dado influir en la marcha de la cosa pública, a todos interesa ésta por necesidad; porque siendo el fin del Estado declarar y hacer efectivas las reglas que han de presidir la vida individual y colectiva, no hay nadie a quien tal sea indiferente; y todos, quiéranlo o no lo quieran, son colaboradores de la obra social en esta esfera, porque, el que menos, contribuye en ella participando en la creación o transformación de las costumbres jurídicas y políticas (Azcárate, 1978: 172).

En este punto, el organismo ético krausista se aproxima a la doctrina del organicismo naturalista en la que: "El Estado se produce y se nos revela como una síntesis incesantemente renovada de la acción de todos sus factores constitutivos; los que formamos el Estado lo hacemos, y a nadie que viva en él le es extraño" (Posada, 1928: 476), apreciando cierta evolución en su concepto. Si bien en un primer momento, Posada opta por una acepción amplia, a tenor de su sentido gramatical, al definir el término Estado como "la manera de ser o estar constituida políticamente la comunidad bajo una forma de organización determinada", sin impedir que de su unidad se vayan diferenciando las instituciones contenidas en él como la familia, la iglesia, las asociaciones municipales, gremios..., como unidades orgánicas que integran el Estado, unidad orgánica superior. Con el tiempo se inclinará por una definición télicojurídica, en la que, al analizar el Estado en su esencia, considere la finalidad jurídica a la que tiende como garante del ordenamiento jurídico (Santamaría de Paredes, 1893: 66).

La propuesta de Estado tutelar se obtiene ahondando en él, porque "el Estado es cosa de adentro, es una labor de su fuerza inmanente", ofreciendo una definición teleológica por ser la que permite conocer su porqué, dado que el Estado no es una realidad simple cuya existencia responda a un mero capricho de la organización social, sino que en un Estado constitucional es a quien le corresponde el poder soberano en el cumplimiento del fin jurídico. En este sentido, junto al interés prestado al aspecto formal, no era menos importante la determinación de los fines del Estado bajo su aspecto positivo porque, como señala Holtzendorff (1888: 198) “no tendrá base sólida, seguramente, sistema 
político alguno que de antemano no resuelva tal cuestión. Ni sería fácil apreciar, por otra parte, la legitimidad y la moralidad de los actos políticos, sino considerándolos en su relación y armonía con las aspiraciones y fines supremos del estado".

En la determinación del fin del Estado se centra la conceptualización del término. Su existencia como entidad social depende del objeto de su acción; y de ahí que, como advierte Giner de los Ríos (1880: 225-264, 240), cuantas teorías han tratado de explicar su naturaleza, lo consideren como un orden teleológico, como un órgano o instrumento adecuado para satisfacer cierto fin. Pretender dar una definición puramente formal en la que se prescinda de la idea de fin, nunca podrá ofrecer una definición completa del mismo; antes bien, omitiría una de sus notas características que le permiten distinguirlo de aquellas otras formaciones que buscan equiparársele, e incluso superarlo.

La existencia del Estado como unidad orgánica superior no obedece en la filosofía krausista a una decisión arbitraria, sino que esa existencia ha de tender a un fin: si el Estado existe ha de tener su razón de ser, ha de tener un fin o fines que cumplir. En este sentido, y frente a las doctrinas del momento, Posada le asigna una finalidad única: garantizar la observancia del derecho avalando la libertad individual y la justicia social. Esta finalidad jurídica de influencia gineriana, le permite superar la visión estática del Estado para constitucionalizarlo en un conjunto de instituciones permanentes que unen a los hombres para ordenar su vida colectiva según un sistema preestablecido a través del derecho constitucional, no entendido éste como mera abstracción, sino como una realidad que se adapta por el devenir de la historia. A partir de este momento, el Estado se convierte en institución para el derecho; es decir, el derecho político como derecho del Estado: "es derecho para el derecho" (Posada, 1897: 121) al reducir el Estado a un cierto orden o reglamentación a la que debe someterse la comunidad amparada en una Constitución -escrita o no- que garantice la aplicación del Derecho al Estado. Esta afirmación le permite, al igual que a Kelsen, superar la dualidad EstadoDerecho, al negar su distinción.

Para garantizar la finalidad a la que el Estado tiende, Posada sustituye la tradicional teoría de la división de poderes con la que Montesquieu iniciara en 1748 el moderno estado constitucional con la publicación de Del espíritu de las leyes, por la teoría de división de funciones, en la que el Estado, al igual que el organismo humano, lleva a cabo sus funciones a través de una previa actividad constante, que se concreta en poderes en la medida en que se organizan en torno a una institución. En este sentido, y teniendo en cuenta que no toda función realizada por el Estado se convierte en poder, Posada distribuye las funciones entre los distintos poderes, para tratar de explicarlas a partir de la esencia y el fundamento como unidad orgánica por el que la institución se constituye, sin perjuicio de que en la práctica se desdoble en operaciones distintas. Se supera por tanto, la idea roussoniana del pacto como causa y origen del contrato social y, mediante el organicismo krausista, sitúa el origen de la soberanía del Estado en su analogía con todo organismo natural, porque primero surge la función, es decir, el derecho, y solo ante su existencia se desarrolla el órgano -Estado Soberano- necesario para garantizar su funcionamiento, dado que toda necesidad requiere de un acción que con el tiempo se constituya en una función, para terminar formalizada en un órgano que la realiza de forma ordenada y reflexiva.

La dimensión espiritual y finalista del liberalismo orgánico convierte al Estado en un instrumento capaz de garantizar la observancia del derecho, en el que el propio Estado queda sujeto a las reglas jurídicas, "convirtiéndolo de soberano asistido del poder de dominación, en soberano sí, pero que se acomoda, por "autodeterminación al Derecho" (Posada, 1931b: 78). Como se analizará más 
adelante, en la teoría del Estado de influencia krausista, la soberanía se espiritualiza, superando un punto de vista material entendido como privilegio del más fuerte, para dotarle de un sentido jurídico, como poder de decisión propio de toda persona autónoma inserta en el orden social. Desde esta soberanía humanizada se propone la sustitución del término "soberanía" por el de "autonomía", al reducir el poder soberano del Estado a la capacidad jurídico-política del grupo humano que lo integra para elaborar y respetar el ordenamiento jurídico.

En la medida en que el Estado es considerado institución para el derecho, y con la intención de explicar su existencia a partir de la realidad, Posada vincula su estudio a la sociología; personifica el Estado en la sociedad de la que procede -estado no oficial- en la que cada uno de sus miembros -como ser racional y libre cumple el derecho- se convierte en estado a nivel individual, esencia de la personalidad moral del Estado referida por Hauriou. Por tanto, la actividad que exige el derecho se ha de llevar a cabo por un ser capaz de valorar la legalidad de los actos, es decir, por la persona como ser racional y libre. Entre las distintas cualidades del sujeto, la que al Estado le interesa es su condición jurídica, convirtiéndolo en agente activo del derecho, al transformar al hombre interior bajo el convencimiento moral del esfuerzo de todos hacia el ideal de la humanidad.

Este finalismo jurídico al que tiende Posada y cuya observancia depende del ser racional, es el que justifica la transformación del hombre interior a través de un regeneracionismo pedagógico. Renovación moral de la vida española que encuentra acomodo en las tendencias regeneracionista que, frente a posturas conservadoras y autoritarias, proponen la educación social como programa político por el que educar "al hombre que piensa, siente y quiere" (Ortega y Gasset, 1916: 262) a fin de corregir la inoperancia de un régimen representativo que había permitido que "el pueblo haga por sí solo la educación, y la haga parcial y egoísta, siguiendo vuestro ejemplo y volviéndolo contra vosotros" (Sela, 2007: 55).

La propuesta regeneracionista, tan ligada al reformismo social, no plantea ni una sociedad completamente igualitaria ni admite una jerarquización social, antes bien, sobre la base de que el Estado "se hace por sus miembros", plantea una vía intermedia en la que instruir al ciudadano como vía preventiva con la que lograr un régimen democrático estable, mediante su integración social en un gran cuerpo titular de la soberanía nacional, porque "así como los pueblos civilizados ejercen de derecho y por deber una tutela sobre los que no lo están, y las clases sociales superiores sobre las inferiores, de igual modo los hombres maduros y experimentados tiene el derecho y el deber de preparar las nuevas generaciones para que puedan mañana regir dignamente su vida y prestar a la sociedad los servicios que esta exige de todos sus miembros" (Azcárate, 1978: 192). Una tutela de las generaciones maduras para que las nuevas, "adquieran la suficiente conciencia de los hombres y de las cosas, se interesen por el régimen atinado de la política nacional, penetren en lo posible las soluciones de los graves problemas de la gobernación del Estado, sientan, en fin, piensen y quieran con criterio ilustrado" (Buylla, 1890: 325), y participen a través del sufragio en la institución representativa dependiendo de la posición que ostenten en la pirámide, simbolizada por Posada, "cuya base fuera la masa social entera, y la cual se va estrechando a medida que la participación de los miembros que componen el estado, en la vida política, es más estrecha y reflexiva", y continua afirmando que lo que gana en intensidad lo pierde en extensión; es decir, que cuanto más atención y cálculo y capacidad pide la acción política, son menos los que están en condiciones de efectuarla (Posada, n.d. b: 2627).

Pese a que la participación social de una minoría cualificada pudiera ser tildada de un elitismo democrático ante la jerarquización de los componentes sociales, 
la interdependencia y equilibrio entre el individuo y la sociedad garantizaba un desarrollo armónico que le distanciaba de la teoría elitista que consideraban a la masa como materia inerte, incompetente e ingobernable. El krausismo trata de cumplir una función integradora a través de la educación, que se erige en una pluralidad de órdenes diversos con estructuras y fines específicos -la familia, el municipio, los sindicatos, la iglesia, la universidad...- pero de base organicista social que ve en el Estado político un instrumento con el que logar el ideal jurídico en la proclamación del imperio del Derecho, sustituyendo la idea de mando como poder coactivo, propio de un estado totalitario, por la de ley obligatoria para el propio mando.

En el elemento constituyente propuesto por Posada, el poder como instrumento del Estado, no manda por ser poder, sino porque así lo exige el imperio del derecho. Esta revisión del liberalismo que plantea el liberalismo democrático exige una reforma de la constitución jurídica de la sociedad y del Estado a través de la implantación de un verdadero Estado de Derecho, en el que se respete un régimen de garantías del ciudadano al hacer compatible los términos soberano y súbdito. De este modo, y pese a que la titularidad de la soberanía tiende a considerar antitéticos los términos, soberano, para referirse al órgano que ostenta el atributo material del poder, sea en manos del monarca o de una minoría privilegiada, frente al término súbdito o masa social sometida a la fuerza del soberano, esta antinomia es difícil de mantener ante una concepción organicista del Estado defendida por Posada, en la que la finalidad jurídica que justifica la existencia del mismo hace innecesario, desdoblar el contenido social en dos partes: el que manda y el que obedece (Posada, 1928: 299). No hay inconveniente, señala el autor, en afirmar que el mismo Estado es soberano y súbdito de sí propio, en la medida en que siendo la soberanía una cualidad distintiva del poder del Estado, el ejercicio de su actividad no le puede corresponder sino al propio Estado, siendo el gobierno el que asume su representación.

\section{La soberanía política como función de Estado}

En la elaboración de toda teoría del Estado junto a la concreción del objeto y el fin al que el Estado tiende, se ha de precisar la titularidad la soberanía política, en torno a la cual se plantean problemas tan complejos como el fundamento del Estado por el que se obliga a obedecer, y la justificación del poder político que, frente al doctrinarismo abstracto, en la filosofía jurídica krausista ofrece la imagen de un Estado intervencionista, como ente real con necesidades que cumplir, y que ha de llevar a cabo las actividades propias para garantizar el cumplimiento del derecho.

La soberanía es un concepto cuya primera aproximación sugiere la idea de función que el Estado materializa de forma inmediata en actos de dirección, mando y coacción. Así, en el proceso histórico de la sociedad occidental, la soberanía se ha distinguido como cualidad de poder o fuerza característica del poder político en Platón y en la Política de Aristóteles, siendo en el pensamiento moderno del constitucionalismo europeo donde alcanza la consideración de fuerza característica del Estado, vinculando el concepto a todo Estado constitucional en el que el poder constituyente manifiesta su voluntad política a través de la Constitución.

La soberanía es la fuerza central, mantenedora de la unidad del estado, y siendo la soberanía del estado, su característica, la supremacía, querrá decir, que sólo el estado, es quien, en su esfera, decide: nadie limitará su acción desde fuera (Posada, 1928: 329-330). 
En opinión de Bluntschli (1880: 403) la expresión "soberanía" nace en Francia; siendo la ciencia francesa la primera que la desarrolla, y Juan Bodino (15301596) quien teoriza sobre la esencia de la soberanía del príncipe desde un punto de vista jurídicopolítico y la eleva a la categoría de principio fundamental de derecho público para convertirla en el elemento central de la organización del Estado. Sin embargo, y frente a este concepto del absolutismo monárquico, la titularidad de la soberanía evolucionará hacia un modelo de Estado donde la soberanía residirá en el pueblo, titular de todos los poderes en el nuevo modelo constitucional. Bajo el nuevo orden político, Posada estudia la soberanía a través del reflejo natural del proceso de su historia capaz de adaptarse a los movimientos políticos, y niega la existencia de un origen pacífico del concepto, por entender que éste se debe a una conquista, "no polémica" -como indicara Jellinek-, sino "bélica" (Posada, 1931a: 79) por alcanzar el poder, dado que "no se ha descubierto este concepto en el gabinete de sabios extraños al mundo, sino que debe su existencia a fuerzas muy poderosas, cuyas luchas forman el contenido de siglos enteros" (Jellinek, 1981: 327). Si en su origen la soberanía fue una noción "política", expresión de una fuerza materializada, con el tiempo, la constitucionalización del poder tiende a espiritualizarlo hacia una concepción ética como última razón del derecho ${ }^{8}$.

Para Orlando, la soberanía es "la fuente de todos los poderes públicos, como un derecho supremo, en el cual todos los derechos particulares encuentran su síntesis y su razón común"9. Definición que responde a la misma etimología de la palabra soberano, soberanus de super, estar situado por encima, que convierte al Estado en aquel que actúa de forma tal, que sus actos no pueden ser revisados, al actuar en última instancia, sin ulterior recurso, de un modo inapelable. Esta definición, pese a ser incompleta no es errónea, en opinión de Posada, y con la que coinciden tanto los partidarios de la soberanía de derecho divino, como los partidarios de la soberanía popular e incluso los doctrinarios. De este modo, pese a considerar la soberanía como un atributo distintivo de poder político y poder del Estado (Posada, 1915: 246-258, 246), con el que poder ejercer la "suprema potestas" o "poder pleno" bien bajo la dirección déspota de un régimen de tiranía, bien de imperio absoluto... viene siendo la posición admitida en toda comunidad política organizada, el reconocimiento de una fuente suprema como es la Constitución.

En el modelo constitucionalizado de Estado defendido por Posada, el ente soberano actúa por sí mismo en la esfera de su propia capacidad racional (Posada, n.d. c: 50). Este concepto tiene su fundamento en la idea de la capacidad jurídica del Estado, en cuanto competente para dirigirse racionalmente; es decir, con aptitud para obrar según reglas propias sobre las determinaciones de su actividad.

Sin embargo, como ya advirtiera Giner de los Ríos (1875: 209), la soberanía no es solo atributo del Estado, sino que se da en todos los círculos de la vida, en el individuo, en la sociedad doméstica..., en la medida en que, "siendo enteramente

8 La expresión soberanía tiene una evolución y así, si en un primer momento se utilizó para identificar el poder de la monarquía, posteriormente, cuando el monarca se somete al texto constitucional, la expresión pasa a identificar la relación del estado con sus súbditos. Asimismo, la expresión sigue utilizándose para referirse a las relaciones internacionales entre Estados; en cuyo caso, soberanía viene a significar independencia de un Estado con respecto a terceros Estados. Distintas formas de entender la expresión "Soberanía", a la que se refiere Merriam en su libro Historia de la teoría de la soberanía, y que recoge Posada en su artículo "La soberanía", 248-249.

9 Definición recogida por Posada (1915: 246). 
independientes en la esfera de su respectiva competencia, no reconoce superior para cuanto dentro de ella le está encomendado". De este modo, la soberanía no queda limitada al ámbito del Estado, sino que es propia de todo individuo en cuanto autónomo e independiente para el cumplimiento de sus fines, vinculando los conceptos poder-autonomía y soberanía, en la medida en que la persona es soberana en la esfera inmanente, porque no se concibe personalidad sin un poder propio de determinación y una independencia para actuar (Posada,1915: 246). En este sentido, y aunque en la ciencia política el término poder se haya limitado a designar la actividad del Estado con la que garantizar el éxito de sus fines mediante el empleo de la fuerza, el poder soberano no es una facultad exclusiva del Estado, sino propia de toda persona o grupo de personas, por reducido que éste sea, en la medida en que disfruta de personalidad propia, con un fin que cumplir y con poder-capacidad-para alcanzarlo (Posada, 1931: 55). Por tanto, si la soberanía es nota común a la persona individual y social, cuando nos preguntemos a quién corresponde la titularidad de la soberanía, la respuesta variará en función del punto de vista adoptado: desde un punto de vista jurídico, toda persona es soberana en la medida en que actúa con libertad. Sin embargo, desde una significación política soberano es el Estado como representante de la soberanía nacional.

Si bien los estados constitucionales no siempre recogen expresamente la titularidad de la soberanía en sus constituciones, recuerda Posada "a un ilustre hombre político" afirmar que a la vista de su devenir histórico "ni por causalidad, hemos tenido la Constitución que necesita España" (Posada, 1931b: 59). De este modo, bajo los prolegómenos constitucionales del Estatuto de Bayona y frente a los defensores de la soberanía histórica de la monarquía absolutista, el exaltado patriotismo tras la invasión napoleónica promulgó la Constitución de 1812 sobre la base de un poder nacional constituyente que dio paso a un régimen constitucional de separación de poderes y reconocimiento de derechos y libertades individuales, previamente alcanzado en Inglaterra, Francia y Norteamérica. De este modo, en su artículo tercero establecía que "La soberanía reside esencialmente en la Nación" que había de actuar a través de las Cortes, símbolo de emancipación política del Estado y que se verá menguada con la constitución de 18 de junio de 1837, donde "siendo la voluntad de la Nación revisar, en uso de su soberanía, la Constitución política promulgada el 19 de marzo del año 1812", evitó alusión alguna a la soberanía nacional en su texto normativo, limitando su referencia al preámbulo de la ley.

Bajo el reinado de Isabel II, la Constitución de 1845 supuso una degradación del sistema del primer modelo constitucional, en el que al no admitir derechos políticos de carácter general no contiene pronunciamiento expreso sobre la titularidad de la soberanía, que quedó atribuida implícitamente antes a la Monarquía que a la Nación, no siendo por tanto, ni una constitución políticamente liberal, como tampoco lo fue de soberanía social constituyente, dado que tal potestad no residió sino en la potestad constituida de las Cortes con el Rey. Y así, frente a la Constitución de 1837 donde fueron las Cortes Generales, las que, en uso de su soberanía, acordaron revisar la Constitución que "decretan y sancionan" y que la reina se limitó a aceptar, en el preámbulo de la Constitución de 1845 expresamente se atribuye el acto de soberanía a la Reina, cuando dice "hemos venido -habla la Reina- en unión y acuerdo con las Cortes" a decretar y sancionar la Constitución. Es decir, pese a que la soberanía residía en la Nación, se ejercía a través de un pacto en las Cortes con el Rey. Acuerdo que se intentará rectificar en la Constitución ulterior.

Frente a debilidad del primer constitucionalismo y para afirmar la esencia de un régimen representativo adulterado se recurrió a las constituyentes que 
elaboraron la Constitución non nata de 1856 en cuyo artículo primero disponía que "Todos los poderes públicos emanan de la nación, en la que reside esencialmente la soberanía"10, y que, pese a que nunca llegó a ser promulgada, merece interés el trámite parlamentario, la convocatoria de elecciones constituyentes y el restablecimiento de la constitución de 1845, pero sin Isabel II, que conducirá en septiembre de 1868 bajo la voz de "soberanía nacional", al relevo del primer modelo constitucional hacia un régimen efectivo de libertades públicas con la promulgación por las cortes constituyentes de la Constitución monárquica de 6 de junio de 1869, cuyo carácter se define en su preámbulo al recoger expresamente: "La nación española, y en su nombre las Cortes Constituyentes elegidas por sufragio universal decretan y sancionan la siguiente Constitución".

Ante un texto constitucional encabezado por una declaración de derechos del ciudadano, se incluye un título general bajo la rúbrica "De los poderes públicos" en cuyo artículo 32 se enuncia que "La soberanía reside esencialmente en la Nación, de la cual emanan todos los poderes", y que pese al cambio de forma constitucional de 1873 se mantendrá en vigor hasta la intervención militar de 1874, y con ella la restauración del constitucionalismo histórico en la figura de Alfonso XII con la que Cánovas logrará imponer una Constitución sin proceso constituyente en unión del Monarca con las Cortes donde, pese a respetar el título primero "De los españoles y sus derechos", se elude la titularidad de la soberanía, al retomar los anteriores principios de soberanía compartida, propiamente incompatibles, en opinión de Azcárate (1978: 107), con la soberanía nacional.

El constitucionalismo democrático se retomará con fuerza en 1931 tras la apariencia de un régimen pseudodemocrático carente de fluido ético denunciado por Posada al defender, junto a Azcárate, que la soberanía nacional, única fuente de poder era "la única solución justa y conveniente, y la única posible del problema político de nuestros días"11. En estas fechas, tránsito del frágil Estado liberal hacia un Estado social de derecho, Posada planteó con urgencia la revisión de los fundamentos de la representación política y social del Estado, proponiendo un corporativismo democrático por el que integrar a los intereses sociales en la estructura del Estado y ello porque "toda revisión constitucional de fondo entrañará necesariamente la revisión de las bases del régimen electoral, a fin de ver de qué modo afecta a la significación de la institución democrática del sufragio, como función y derecho del ciudadano, el advenimiento a la vida del Estado de las nuevas formas de la personalidad y de la vida colectiva" (Posada, 1931b: 105). Revisión constitucional por la que integrar en la organización estatal a los nuevos intereses, dejando de ser una simple reforma abstracta para ser reflejo de la realidad social.

Su vinculación al partido reformista de Melquiades Álvarez le permite presentar su propuesta, al colaborar como miembro de la subcomisión técnica de la Comisión Jurídica Asesora del Gobierno en el Anteproyecto de la Constitución de la República con la redacción de las "Bases para la Constitución política de España" cuya base primera proponía: "La soberanía reside esencialmente en la nación, de quien emanan los Poderes del Estado. El Derecho en el Estado español emana del Pueblo, y se manifiesta ya sea espontáneamente bajo formas consuetudinarias, ya mediante leyes elaboradas por las instituciones constitucionales organizadas al efecto, con las solemnidades exigidas y según las normas

10 Esta Constitución no llegó a entrar en vigor en España, pese a ser discutida y votada por las cortes constituyentes de 18541856, al promulgarse el Real Decreto de 15 de septiembre de 1856 y con él el restablecimiento de la Constitución de 1845.

11 Prólogo escrito por Posada en SalinasAvilés (Asturias), 1 de agosto de 1931, al libro de Azcárate (1978). 
establecidas por la Constitución" (Ibid: 215). Propuesta que fue rechazada por las Cortes Constituyentes de 1931, "por entender que no deberían superponerse los intereses corporativos o profesionales de los intereses generales a través de los partidos políticos" (Monereo Pérez, 2003: 208), y que le permitirá a Posada retomar su vida universitaria, al ser nombrado decano de la facultad de derecho de la universidad Central, y en 1933 decano honorario de la facultad de derecho de la universidad de Oviedo ${ }^{12}$. Años de crisis durante los que Posada asumirá la presidencia del Consejo Asesor y órgano del Ministerio en materia de conflictos sociales y la presidencia del Instituto Nacional de Previsión hasta que con la llegada del Frente Popular se refugie en su familia y en sus recuerdos. Sus memorias no recogen referencia alguna a esta última etapa, no por falta de recuerdos, sino por la intención de plasmar los pasajes gratos de una vida dedicada a la cátedra y "a mis discípulos", y evitar, así, recordar cualquier acontecimiento ingrato.

El 9 de diciembre de 1931 entraba en vigor un nuevo concepto de norma fundamental, una Constitución fuerte señala Bartolomé Clavero (1986: 117) "frente a la debilidad de la propia tradición", en cuyo preámbulo recogía expresamente que: "España, en uso de su soberanía, y representada por las Cortes constituyentes, decreta y sanciona esta Constitución" bajo el principio de integrar "una República democrática de trabajadores de toda clase, que se organiza en régimen de Libertad y de Justicia y cuyos poderes de todos sus órganos emanan del pueblo".

Desde esta concepción organicista del Estado como una gran institución social, la soberanía individual se integra en una soberanía nacional, al consagrar el dogma democrático de anteponer el bienestar nacional al individual bajo la denominada soberanía del estado, porque esta no es exclusiva de un órganoindividuo, sino que pertenece a toda persona de derecho que forma parte del Estado y que justifica, en opinión de Posada, el intervencionismo de un Estado Constitucional en la medida en que es un Estado que se somete al Derecho.

De este modo, Posada supera las doctrinas que consideraban la soberanía como centro del poder político ${ }^{13}$, y ello porque la soberanía, en su organicismo jurídicosocial no es atributo de ningún órgano específico, sino del mismo Estado, como persona colectiva sociedad política. Esta idea de soberanía política, en opinión de Posada, hay que buscarla en el proceso hacia un constitucionalismo liberal en el que transformar el Estado ente que manda en unión autónoma con la capacidad para regirse, superando la idea histórica de soberanía monista, propia del absolutismo puro, representada en el príncipe no sometido a la ley bajo el axioma "El Estado soy yo", con la fuerza de mando ejercida en un sentido material por alguno de sus órganos, ni siquiera por la misma masa social. Por el contrario, el devenir de los siglos XIX y XX fue gestando un concepto de democracia representativa referido al "más alto poder del Estado", sin atender de forma cuantitativa al modo como se ejerce o en manos de quién se ejerce, sino a favor de la idea de soberanía cualitativa en su fuero interno como dominación sobre sí, con autonomía y en la relación externa con independencia, garantizando la compatibilidad de soberanías de distintos Estados en el cumplimiento del fin jurídico al que tienden:

12 Por Decreto de 30 de septiembre de 1933, Gaceta de Madrid de 5 de octubre del mismo, se nombra a Posada decano honorario de la facultad de derecho de la universidad de Oviedo, A. G. A. 4/9613.

13 Nos limitamos a mencionar algunas de las teorías qué considerando la soberanía como el eje del poder, varían en el sujeto activo: la soberanía de origen divino ejercida a través de sus representantes; las doctrinas liberales que atribuyen la soberanía al pueblo; las eclécticas... 
El poder tiene por fin hacer posible que el Estado cumpla su función propia, que no es otra que velar por el cumplimiento del derecho, haciendo efectivas las condiciones necesarias para que el hombre pueda realizar su destino (Azcárate, 1978: 85).

Esta interpretación de la noción de soberanía política como garante del cumplimiento del derecho, aporta la idea de límite jurídico del poder del soberano a la que Posada denomina "espiritualización de la soberanía política", para entenderla bajo la idea de dominio del Estado sobre sí mismo y bajo el derecho, y no como fuerza material al servicio de una dominación ciega:

La espiritualización de la soberanía es una idea que corresponde, en el problema concreto del poder, a la más general de la concepción del Estado, soberano, sí, pero en el derecho, o sea sometido al derecho, y ello merced, principalmente, a la transformación de la noción de soberanía como expresión de dominación del hombre sobre el hombre en la noción de soberanía como fórmula expresiva del "dominio del Estado sobre sí mismo" y por el derecho (Posada, 1931-a: 88).

Bajo una soberanía humanizada, el Estado respeta la capacidad jurídica individual porque "del propio modo que el ser humano, adquiere la plenitud de su personalidad cuando posee la mayor capacidad para dirigirse, el estado habrá adquirido la plenitud de su soberanía, cuando sea una personalidad política tan coherente, que tenga la capacidad de ordenar su fuerza interna, dirigirla, formar su derecho y hacerlo respetar sin violencia" (Posada, 1910: 436- 449), en la medida en que el hombre, como ser racional, encuentra en su conciencia la justificación de un poder político y la necesidad de cumplirlo, bajo la significación del denominado fluido ético ${ }^{14}$. La soberanía espiritualizada como poder ético, conlleva que la soberanía deja de ser un mero poder de dominación para generar un poder ético, capaz de elaborar y hacer efectivo un orden jurídico justo y eficaz en la conciencia colectiva, que se impone tanto a gobernantes, gobernados; así como sobre el propio Estado en su condición de soberano.

La idea de un Estado con soberanía espiritualizada supone que el soberano debe estar también sometido a las reglas jurídicas, se somete al derecho, se domina a sí mismo y sin perder la calidad de superioridad, "no atropella al débil -al estado menos fuerte-; es capaz de respetar cosa tan espiritual como un derecho, sin que venga el derecho apoyado en cañones" (Posada, 1915: 37). Y ello porque como señala Posada (1928: 320-323), la soberanía "es un poder espiritual y ético... La fuerza obligatoria -validez y eficacia- de las decisiones de poder político tiene su origen en la conciencia de la personalidad del estado, y se mantiene en cuanto éste es capaz de darse cuenta del valor de tales decisiones, y en cuanto son exigidas por la atracción del fin racional que debe guiar su conducta".

\section{Epílogo}

Desde la concepción orgánicosocial de influencia krausista, Posada, sin ser considerado un constitucionalista en sentido estricto, sí fue un "demócrata" que, desde su cátedra Elementos de derecho político y administrativo español, trató de

14 Prólogo de Pérez Serrano a La idea pura del estado de Posada (1943: 20). 
dar una explicación más profunda del Estado, centrado en el hombreciudadano de un organismo social, en su intento por superar un liberalismo individual hacia un "liberalismo social", con el que transmitir los valores, principios e inclinación por un Estado democrático, no solo desde un punto de vista teórico, a través del estudio de la constitución vigente, sino mediante una disciplina enciclopédica por la que concretar en quién y cómo se ejerce el poder del Estado ${ }^{15}$. Un nuevo liberalismo socializado, en el que a través de la acción tutelar de un Estado intervencionista se forme a la élite directiva comprometida con la libertad y la justicia social con la que garantizar la soberanía nacional.

Si bien el estado constitucional consolidará la soberanía nacional a lo largo de los siglos XIX y XX, el carácter eminentemente ético de la doctrina krausista que defendió Posada le privó de la viabilidad necesaria para llevarla a la práctica, dado el sentido ideal e irrealizable al que queda reducida. Esta teoría "ideal" derivó al final de su vida en la crisis del Estado; crisis en la que Posada quedó inmerso al ver la pérdida de los valores éticos por los que luchó. La crisis del Estado en su forma y en su esencia, le hizo perder la confianza en la elaboración de un nuevo derecho que combinase la libertad individual con el bienestar social, consciente de que toda revisión constitucional de la representación política y de sus instituciones deberían realizarse interpretando la realidad social a fin de quedar reflejada en la organización del Estado constitucional.

\section{Bibliografía}

Azcárate, G. (1978). El régimen parlamentario en la práctica. Madrid: Tecnos. Bluntschli, J.G. (1880). Derecho público Universal. 3 vols., Madrid: Góngora.

Buylla, A. (1890). Sobre la necesidad actual de la educación del obrero. Boletín de la Institución Libre de Enseñanza, 330, 325-330.

Clavero, B. (1986). Evolución histórica del constitucionalismo español. Madrid: Tecnos.

Fuentes, J.F. (2004). Mito y concepto de pueblo en el siglo XIX: una comparación entre España y Francia. Historia contemporánea, 28, 95-110.

Gallego Anabitarte, A. (2002). Formación y enseñanza del derecho público en España (17692000). Un ensayo crítico. Madrid: Marcial Pons.

Giner de los Ríos, F. (1875). La soberanía política. En F. Giner de los Ríos. Estudios jurídicos y políticos (pp. 200-225). Madrid: Librería General de Victoriano Suárez.

Giner de los Ríos, F. (1875). La política antigua y la política nueva. En F. Giner de los Ríos. Estudios jurídicos y políticos (pp. 63-199). Madrid: Librería General de Victoriano Suárez.

Giner de los Ríos, F. (1880). El individuo y el estado; el gobierno y la nación. Revista General de Legislación y Jurisprudencia, 57, 225-264.

Holtzendorff, F. (1888). Principios de política. Introducción al estudio de la ciencia política contemporánea. Madrid: Librería Fernando Fe.

Jellinek, G. (1981). Teoría general del estado. Buenos Aires: Albatros.

Martín, S. (2015). Liberalismo e historia en el derecho político. Semblanza de Manuel Colmeiro y Peinado (1818-1894). En J. Varela Suanzes-Carpegna (ed.). Siete maestros del derecho político español (pp. 37-70). Madrid: Estudios Constitucionales.

15 Para Jellinek (1981: 1014), la política es la ciencia práctica del Estado o ciencia aplicada; es decir, aquella que estudia el modo como el estado puede alcanzar determinados fines. 
Monereo Pérez, J.L. (2003). La reforma social en España: Adolfo Posada. Madrid: Ministerio de Trabajo y asuntos sociales.

Morán Martín, R. (2016). Crónica y actitud de un constitucionalista. La tesis de Adolfo Posada sobre la titularidad de la soberanía. Estudios de Deusto, 64, 361375.

Murillo Ferrol, F. (1951). Nación y crisis. Revista de Estudios Políticos, 47-76.

Ortega y Gasset, J. (1916). La pedagogía social como programa político. Boletín de la Institución Libre de Enseñanza, 678, 257-268.

Posada. A. (n.d. a). Ciencia Política. Barcelona: Manuel Soler.

Posada, A. (n.d. b). El sufragio según las teorías filosóficas y las principales legislaciones. Barcelona: David Soler.

Posada, A. (n.d. c). Derecho usual. Madrid: Ediciones de la Lectura.

Posada, A. (1884). Principios de derecho político. Introducción. Madrid: Revista de Legislación.

Posada, A. (1889). La enseñanza del derecho en las universidades. Estado actual de la misma en España y proyectos de reforma. Oviedo: Imprenta de la Revista de las Provincias.

Posada, A. (1897). Tratado de derecho administrativo: según las teorías filosóficas y la legislación positiva. Madrid: Librería General de Victoriano Suárez.

Posada, A. (1906). Derecho político comparado. Capítulos de introducción. Madrid: Librería General de Victoriano Suárez.

Posada, A. (1910). Conferencias del Dr. Adolfo Posada de Ciencia Política, Archivos de pedagogía y ciencias afines, 7, 21, 436- 449.

Posada, A. (1928). Tratado de derecho político. Madrid: Librería General de Victoriano Suárez.

Posada, A. (1931a). Hacia un nuevo derecho político. Madrid: Páez.

Posada, A. (1931b). La reforma constitucional. Madrid: Librería General de Victoriano Suárez.

Posada, A. (1934). La crisis del estado y el derecho político. Madrid: Bermejo impresor.

Posada, A. (1943). La idea pura del estado. Madrid: Revista de derecho privado.

Posada, A. (1980). Breve historia del krausismo español, Oviedo. Universidad de Oviedo.

Posada, A. (1983). Fragmentos de mis memorias. Oviedo. Universidad de Oviedo.

Santamaría de Paredes, V. (1893). Curso de derecho político. Madrid: Establecimiento tipográfico de Ricardo Fe.

Sela, A. (2007). Extensión universitaria. Oviedo: Universidad de Oviedo.

Soria, M. (2004). El trabajo de cátedra de Adolfo Posada. En A. Mora Cañada (ed.). La enseñanza del derecho en el siglo XX. Homenaje a Mariano Peset (pp. 503-515). Madrid: Dykinson.

Varela, J. (2015). Un influyente maestro del derecho político español: Vicente Santamaría de Paredes (18531924). En J. Varela Suanzes-Carpegna (ed.). Siete maestros del derecho político español (pp. 7394). Madrid: Estudios Constitucionales. 